\title{
O Papel da Enfermagem na Sessão de Hemodiálise
}

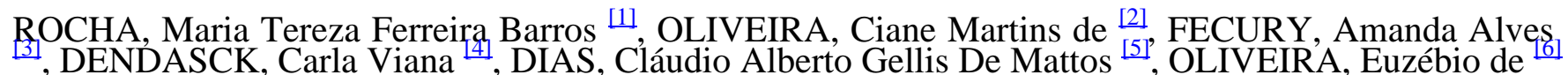
ROCHA, Maria Tereza Ferreira Barros; et.al. O Papel da Enfermagem na Sessão de Hemodiálise. Revista Científica Multidisciplinar Núcleo do Conhecimento. Ed. 11, Ano 02, Vol. 04. pp 39-52, Novembro de 2017. ISSN:2448-0959

\section{RESUMO}

Este estudo considera mecanismos importantes referentes ao papel do enfermeiro na sessão de hemodiálise. Visa também de acordo com o referencial bibliográfico mostrar complicações comuns neste segmento. O estudo tem o objetivo de identificar e reconhecer a importância da enfermagem na sessão de hemodiálise. A pesquisa baseou-se em estudo bibliográfico e artigos. Os resultados apontam que na sessão de hemodiálise o papel do enfermeiro abrange entre outros aspectos a prevenção por meio de orientação ao paciente, no intuito de não agravar ou comprometer ainda mais a situação. Esse tipo de contato por meio de diálogo entre o enfermeiro e o paciente é de fundamental importância, pois há ocorrência em que o paciente sofre de alterações múltiplas necessitando assim, da presença desse profissional. Com isso, conclui-se que a efetivação de um trabalho de orientação, educação e assistência ao paciente, além de permitir ao enfermeiro a realização do diagnóstico prévio, pode evitar possíveis complicações na sessão de hemodiálise.

Palavras-Chave: Hemodiálise, Paciente, Enfermeiro, Educação.

\section{INTRODUÇÃO}

Os rins são responsáveis pela eliminação dos resíduos provenientes da digestão dos alimentos depois que o organismo aproveitou-se de todos os seus elementos nutritivos. Quando os rins não estão trabalhando apropriadamente, é necessário fazer ajustes na dieta para que o organismo não se sobrecarregue com esses resíduos (ELIZA, 2009).

Essa medida é considerada importante a fim de que o problema ocasionado nos rins não gere futuramente uma Insuficiência Renal Crônica (IRC). 
A Insuficiência Renal Crônica (IRC) refere-se à perda progressiva e irreversível da função renal. Se não houver tratamento, levará o paciente a morte. A IRC pode ser tratada por meio da hemodiálise em pacientes selecionados, cujo principal critério é ter uma função cardíaca estável (DALGIRDAS, 2003).

Diante do exposto, este artigo revela sua importância na abordagem desse tema em que evidencia o papel do enfermeiro na sessão de hemodiálise.

As sessões de hemodiálise pertencem à área de nefrologia que apresenta um conhecimento amplo e diversificado. E é nesse sentindo que se busca aqui demonstrar qual é de fato o papel e a importância do enfermeiro perante o paciente que está em processo de tratamento na hemodiálise.

A hemodiálise é o processo de filtragem e depuração do sangue de substâncias indesejáveis como a creatinina e a uréia que necessitam ser eliminadas da corrente sanguínea humana devido à deficiência no mecanismo de filtragem nos pacientes portadores de IRC. Na hemodiálise, a transferência de solutos ocorre entre o sangue e a solução de diálise através de uma membrana.

Neste sentido, o papel do enfermeiro para melhor desempenhá-lo, apropria-se da Sistematização da Assistência de Enfermagem (SAE), para basicamente poder aplicar conhecimentos na assistência ao paciente e caracterizar sua prática profissional, contribuindo na definição de sua função da melhor forma possível.

Com isso, este estudo poderá trazer benefícios e contribuições aos enfermeiros, em especial ao nefrologista, pois destacará o seu papel durante as sessões de hemodiálise, demonstrando assim sua importância para um melhor tratamento.

Diante desse contexto, o presente artigo objetivou identificar o papel do enfermeiro na sessão de hemodiálise, considerando suas atribuições para com o paciente.

\section{REFERENCIAL TEÓRICO}

De acordo com Riella (2001) entende-se como hemodiálise, um processo no qual um rim artificial (hemodialisador) é usado para depurar o sangue.

Sendo assim, compreende-se que a pessoa que perde sua função renal de forma crônica, deverá ser auxiliada e ser orientada a fazer o tratamento de hemodiálise. Com isso, a hemodiálise terá o papel de substituir a função dos rins, depurando o plasma sanguíneo por meio de um filtro ligado a um rim artificial - máquina de hemodiálise (RIELLA, 2001).

Verifica-se que neste tratamento os pacientes tornam-se dependentes desta máquina para sobreviver, pois ela realiza a função do rim danificado filtrando e eliminando as impurezas do sangue como uréia, creatinina e excesso de líquidos (RIELLA, 2001).

Constata-se que durante a sessão de hemodiálise, são utilizadas duas agulhas que são inseridas na fístula, sendo uma para enviar o sangue para o hemodialisador, que é uma espécie de filtro, e a outra para retornálo para o paciente (RIELLA \& MARTINS, 2001). 
A duração e a frequência das sessões de hemodiálise serão estabelecidas de acordo com a quantidade de diálise necessária para que o paciente obtenha a maior depuração possível de solutos, para a manutenção do equilíbrio hidroeletrolítico e ácido-básico, para o controle da pressão arterial e de um estado nutricional adequado com o mínimo de efeitos adversos e inconvenientes (BARROS, 1999).

Em tempos atuais, nota-se que há um grande avanço no que se refere à garantia e a qualidade das máquinas que fazer o tratamento de hemodiálise, tornando desse modo, o tratamento mais confiável. (DAUGIRDAS, 2003).

Segundo Daugirdas (2003), considera-se a enfermagem como sendo o grupo de profissionais que mais apresenta participação direta no que diz respeito ao processo que abrange a hemodiálise, abrangendo dessa forma o desempenho e a atuação desses profissionais na solução de possíveis complicações que porventura venham surgir durante o tratamento.

Para Daugirdas (2003), a presença e a ocorrência das complicações são consideradas elevadas. Observase que ultimamente a hemodiálise visa reverter não apenas ou simplesmente os sintomas urêmicos, mas tem como meta mais ampla, reduzir as complicações pertinentes peculiares ao procedimento e a redução do risco de mortalidade. Em função disso, os profissionais que atuam na enfermagem precisam se manter sempre contemporâneos, ligados aos temas atuais a fim de assegurar um tratamento que seja pautado na segurança e eficácia, com a intenção de garantir a qualidade no tratamento ao paciente renal crônico.

\section{METODOLOGIA}

A metodologia utilizada neste estudo diz respeito a uma revisão de literatura com base em dados de LILACS e SCIELO, além de contemplar outras publicações avaliadas como sendo de grande relevância em território brasileiro. Cujo caminho metodológico seguido, alicerça-se nas leituras que exigiram reflexão, e exploração do material selecionado.

A revisão literária foi realizada no período de Agosto de 2013 a Fevereiro de 2014. Utilizaram-se como base os seguintes descritores: hemodiálise, trabalho de enfermagem, paciente e complicações.

Inicialmente ocorreu a leitura prévia de 26 artigos pesquisados. Em seguida, foram selecionados 16 artigos que serviram de base para a estruturação desta pesquisa.

Para realizar a análise referente às informações pesquisadas empregou-se a ordenação dos dados, sendo depois classificada a análise final dos mesmos, guiando-se pelas determinações de Minayo (2008).

Em seguida, a análise dos dados coletados adotou a técnica de análise temática. Porém, utilizaram-se outras obras importantes que também serviram de suporte para a concretização do estudo em questão (MINAYO, 2008).

Analisou e aproveitou-se como critério de inclusão trabalhadores de enfermagem que atuam na sessão de hemodiálise, além de artigos apresentados na íntegra disponíveis na base de dados utilizados para fazer esta pesquisa. 
Toda a literatura selecionada para a construção deste trabalho possui publicações entre os anos de 1999 a 2013.

\section{RESULTADOS E DISCUSSÃO}

Ao longo dos anos ocorreram grandes mudanças no que concerne ao papel do enfermeiro na sessão de hemodiálise. Para demonstrar isso, pesquisou-se para este estudo, bases bibliográficas e pesquisa on line voltadas para enfermagem, hemodiálise e estudo da nefrologia. Onde se encontrou várias obras incluindo 16 artigos, monografias e revistas que foram selecionados apresentando sua publicação no período de 2004 a 2013, servindo de alicerce para a realização desta pesquisa, com um olhar diversificado de autores que direcionam seu trabalho para o papel do enfermeiro na sessão de hemodiálise.

$\mathrm{O}$ crescimento e o aumento de pacientes apresentando problemas renais demonstram que o tratamento hemodialítico no Brasil vem crescendo rapidamente no decorrer dos tempos. Sabe-se que muitas são as causas de ataque renal, sendo que algumas das doenças renais têm seu tratamento sem deixar consequências graves. Porém, constata-se que outras doenças motivam o comprometimento da função renal e evoluem de maneira rápida ou lenta para a insuficiência renal crônica (JUNIOR, 2004).

Em estágio mais adiantado, sabe-se que os rins não conseguem mais garantir a normalidade do meio interno do paciente. A literatura mostra que estudos indicam que portadores de hipertensão arterial, de diabetes mellitus ou história familiar para doença renal crônica têm maior probabilidade de desenvolverem doença renal crônica (JUNIOR, 2004).

\subsection{A importância da enfermagem no tratamento da hemodiálise}

Inicialmente é pertinente relatar que se encontra na Portaria ${ }^{\circ} 154$ de 15 de junho de 2004 a instituição de normas técnicas para promover de forma eficaz todo o funcionamento relacionado aos Serviços de Terapia Renal Substitutiva, além de estabelecer normas para a organização desses estabelecimentos junto ao Sistema Único de Saúde (SUS) (BRASIL, 2004).

A criação dessa Portaria é de suma importância para que seja provida a eficiência do trabalho referente ao atendimento de pacientes renais.

Verifica-se ainda na mesma Portaria, que para cada 35 pacientes, a unidade de Hemodiálise deve ofertar um médico que seja nefrologista, possuindo o título de especialidade registrado no Conselho Federal de Medicina; além da presença de um enfermeiro para cada 35 pacientes, devendo possuir treinamento em diálise reconhecido pela Sociedade Brasileira de Enfermagem em Nefrologia, e ainda um técnico ou auxiliar de enfermagem para cada 4 pacientes por turno de hemodiálise (BRASIL, 2004).

Diante do exposto, a enfermagem no tratamento de hemodiálise apresenta grande relevância no que tange a observação ininterrupta dos pacientes no período em que ocorrer a sessão de hemodiálise, podendo a enfermagem vir a ajudar a salvar vidas e podendo também evitar as possíveis complicações, à medida que se realiza o diagnóstico precoce e preciso de intercorrências.

Sendo assim, é muito importante que o paciente tenha extrema confiança nos profissionais de enfermagem, e que possa existir entre eles uma relação mútua de segurança. Certamente, a equipe de 
enfermagem diante do seu papel profissional, precisa ser prestativa, atenciosa aos pacientes e deve estar sempre alerta para intervir quando necessário, a fim de garantir a saúde do paciente do tratamento de hemodiálise (MEDSI, 2003).

É comum observar que a presença das complicações é muito grande na sessão de hemodiálise. Diante disso, a hemodiálise busca a reversão não somente dos sintomas urêmicos, mas também a redução das complicações que são inerentes ao próprio procedimento e a diminuição do risco de mortalidade (MEDSI, 2003).

Diante do contexto apresentado, compreende-se que é de extrema importância que os profissionais de enfermagem estejam sempre se atualizando, estudando e se aprimorando cada vez mais para ofertar ao paciente renal crônico um tratamento com qualidade e humanizado com maior segurança.

\subsection{O papel do enfermeiro e um trabalho voltado para a assistência, educação e prevenção dos pacientes na sessão de hemodiálise.}

O enfermeiro no exercício de sua função na sessão de hemodiálise possui algumas atribuições, sendo esse profissional o responsável por fazer nesse setor curativos em pacientes com permicarde, em veia subclávia e femural, além disso, o enfermeiro tem a incumbência de ligá-los a máquina (OLIVEIRA, 2008).

É importante saber que o enfermeiro exerce o papel de dá assistência ao paciente de forma integral, contemplando-o como um todo, criando uma relação mútua de confiança e de segurança entre paciente e enfermeiro, dando prioridade aos cuidados necessários ao seu tratamento.

Cabe a ele ainda, garantir o correto uso de materiais e equipamentos, orientando, supervisionando e avaliando. Cuidando também da qualidade do ambiente de segurança, procurando o conforto do paciente e da equipe.

É indispensável e muito importante que o enfermeiro tenha, além do embasamento científico, a competência e habilidade técnica pertinente a seu próprio ofício profissional, é necessário que apresente e tenha noção e aprofundamento dos referentes aos aspectos que considerem os sentimentos e as reais necessidades dos pacientes no tratamento de hemodiálise (OLIVEIRA, 2008).

O objetivo da assistência de enfermagem neste setor é identificar e monitorar os efeitos adversos da hemodiálise e complicações decorrentes da própria doença, desenvolvendo ações educativas de promoção, prevenção e tratamento (OLIVEIRA, 2008).

Um fato relevante a ser analisado pelo enfermeiro refere-se à educação do paciente diante às cobranças determinadas pelo tratamento, pois o conhecimento mais profundo sobre sua doença, tratamento e possibilidades de reabilitação pode auxiliá-los no enfrentamento de situações que causam estresse vivenciado no cotidiano hemodialítico (BARBOSA, 2010).

Sendo assim, nota-se que o enfermeiro no exercício do seu papel profissional, deve constituir ações educativas para ocasionar um tratamento visando a qualidade e eficiência em forma de benefício ao paciente, realizando um trabalho de prevenção quando possível tratar as complicações. Deve ofertar um 
atendimento que seja humanizado, tratando o paciente de forma global e atendendo as suas necessidades humanas básicas de modo que satisfaça o paciente dentro das necessidades apresentadas.

Como se sabe o enfermeiro realiza um trabalho diretamente com o paciente, e por conta desse contato mais próximo, o enfermeiro tem condições de identificar na sessão, expressões faciais, verbais e não verbais, pode constatar ainda situações de obstáculos, sensação de medo e dúvidas quanto à doença e ao tratamento que o paciente está se submetendo.

Diante disso, comprova-se que o diálogo e a observação de forma mais detalhada e clínica são essenciais para a identificação destes fatores e que contribuem certamente para uma melhor interação paciente/enfermeiro, pois proporcionam uma relação de afeto e de comunicação ativa, fazendo com que o paciente vivencie e aceite de uma melhor forma sua doença crônica e a sessão de hemodiálise que sem dúvida é fundamental para o seu tratamento.

É importante alertar que compete ao enfermeiro a função de educar em saúde não somente nos pacientes, como de seus familiares e expandindo para própria equipe de enfermagem. Esta ação por parte do enfermeiro deve ser algo constante e feita de forma estruturada. A ação educativa proporciona aos pacientes e à sua família melhor entendimento e aceitação sobre os procedimentos e confiança na equipe multiprofissional, ensinando-os a adaptarem-se a esta nova realidade para aprender a conviverem da forma mais natural possível.

Deste modo, conclui-se que o enfermeiro deve criar táticas ou mecanismos propícios e específicos ao paciente renal crônico, em hemodiálise, de acordo com a necessidade apresentada em cada paciente, a fim de promover o cuidado e consequentemente o restabelecimento do paciente.

Reconhece-se que toda a Sistematização da Assistência de Enfermagem (SAE) é sem dúvida um aparelho que beneficia a identificação destas estratégias, cabendo ao enfermeiro ter conhecimento e aplicabilidade das fases no processo decorrente de enfermagem.

\subsection{O enfermeiro no diagnóstico de complicações}

As complicações que podem surgir durante a sessão de hemodiálise são: hipotensão arterial, cãibras musculares, náuseas e vômitos, dor torácica e lombar, febre e calafrios, edema agudo de pulmão, síndrome do desequilíbrio, entre outras (FAVA, 2006).

O enfermeiro possui papel de fundamental importância no que se refere ao diagnóstico das complicações ocorridas na sessão de hemodiálise.

A seguir apresentam-se algumas complicações que comumente acontecem e que fazem parte da competência do enfermeiro identificá-las:

\subsubsection{Prurido}

Comumente denominada de coceira, o prurido é o sinal de pele mais importante nos pacientes urêmicos, que se diagnostica pelo enfermeiro na sessão de hemodiálise. Sabe-se também que o prurido ou coceira, é um aparecimento comum nos pacientes que estão em tratamento. Isso se dá em função do efeito tóxico 
que a uremia provoca na pele. As toxinas urêmicas circulantes são responsáveis pelo prurido, que pode desaparecer como o inicio do tratamento de hemodiálise (RIELLA, 2003). É importante lembrar que mesmo com o tratamento da hemodiálise o prurido nem sempre se acalma ou se alivia, correndo o risco até mesmo de acentuar a situação em que se em encontra o paciente diagnosticado com prurido.

A constatação do prurido em alguns pacientes faz notar que a sensação é muito latente e viva que acaba originando escoriações na pele, nas crostas hemorrágicas, nas pústulas e ainda contribui para a formação de nódulos no paciente. As lesões constadas acontecem na face, nas costas, no tronco e nas extremidades do paciente que está com prurido, deixando o mesmo em situação desconfortável e até mesmo constrangedora (CALIXTO, 2003).

Sabe-se que alguns tratamentos utilizados nessa complicação são considerados eficazes como exemplo o uso de aplicações de ultravioleta, o uso de emolientes tópicos à base de cânfora usa de quelantes de fosfato. Verifica-se que o uso de anti-histamínicos por via oral ou endovenosa e a paratireoidectomia está indicada para os pacientes com osteodistrofia e hiperparatireoidismo grave (CALIXTO, 2003). É importante o tratamento quando realizado de forma eficaz por que se utiliza de meios considerados confiáveis para o sucesso do tratamento.

\subsubsection{Náuseas e vômitos}

Nas sessões de hemodiálise é muito comum o enfermeiro identificar a presença de náuseas e vômitos, pois são complicações que acontecem rotineiramente sendo provocada por vários fatores. A grande quantidade dos casos identificados em pacientes estáveis possivelmente esteja ligadas à hipotensão, mas também podem ser uma aparição precoce da síndrome do desequilíbrio (CALIXTO,2003).

Diante disso, o indicado inicialmente é realizar o tratamento da hipotensão, na constatação da mesma. Mas se por ventura, as náuseas e vômitos ainda continuarem sugere-se então o uso de um antiemético para sanar o problema. O certo é que é de extrema importância evitar a qualquer custo a hipotensão durante a diálise para assim evitar maiores danos ao paciente. Em alguns pacientes, a redução da velocidade de fluxo sanguíneo em $30 \%$ durante a primeira hora de diálise pode ser benéfica. No entanto, o tempo de tratamento deve ser prolongado proporcionalmente (DAUGIRDAS, 2003).

\subsubsection{Hipotensão Arterial}

Verifica-se que a incidência de ocorrência da hipotensão é uma complicação que ocorre frequentemente no processo de concretização da hemodiálise, sendo na verdade consequência da grande quantidade de líquidos que é removida do volume plasmático durante uma sessão cotidiana de diálise. (FERMI, 2010). A água acumulada no intervalo Interdialítico é retirada diretamente pelo mecanismo de ultrafiltração.

É importante considerar que outros sinais e sintomas muito comuns constatados dizem respeito às tonturas e a sensação de desfalecimento, dor precordial, sudorese, confusão mental e até mesmo taquicardia. Verifica-se que as principais causas que provocam o aparecimento da hipotensão arterial durante a sessão são: ganho excessivo de peso, hiponatremia, ultra filtração excessiva, uso de antihipertensivos durante a diálise.

O tratamento necessita ser iniciado imediatamente. O paciente deve ser colocado em posição de Trende 
lemburg, deve ser administrados bolus de $100 \mathrm{ml}$ de SF a $0,9 \%$ ou mais se necessário, a velocidade de ultrafiltração deve ser diminuída para o mais próximo possível de zero, Oxigenação adequada e o controle ideal do peso seco (FERMI, 2010).

Feito a correção do evento hipotensivo indica-se fazer uma avaliação cautelosa da frequência e da intensidade da ocorrência para que se possa vim a evitar novas crises. Intervenções de enfermagem como o monitoramento rigoroso dos sinais vitais e observação de sintomas podem ajudar a diminuir drasticamente a ocorrência e a intensividade de episódios hipotensivos nesses pacientes (RIELLA, 2003).

Diante do que foi apresentando anteriormente nota-se, que o tratamento em hemodiálise é avaliado como doloroso, desgastante e muitas vezes padecedor, gerando alterações impactantes não só na vida do paciente, mas também de seus familiares, induzindo-os a adotarem diferentes hábitos de vida em função do tratamento e da doença renal.

Deste modo, entende-se que a sessão de hemodiálise é de grande relevância para o paciente renal crônico, pois possibilita ao mesmo uma melhor qualidade de vida. Nesse aspecto, observa-se a importância do papel do enfermeiro na sessão de hemodiálise por meio de ações que inclui orientação para a mudança de hábitos e costumes, como: adoção de uma dieta rigorosa, com diminuição de proteínas, sódio e potássio; limitação à vida profissional e à atividade física e adesão às rotinas do tratamento, essas informações são de extrema necessidade para o bem-estar do paciente.

Outro ponto a ser considerado nesse processo refere-se ao fator psicológico do paciente que fica comprometido, pois diante da situação em que se encontra se sente incapaz de realizar algumas ações, contribuindo deste modo para abalar sua autoestima. Em decorrência disso, a família exerce um papel fundamental nesta fase de adaptação do paciente, que necessita de apoio e incentivo para não abandonar o tratamento e seguir de forma confiável e positiva.

\section{Conclusão}

O estudo realizado foi de suma importância, pois possibilitou a investigação de forma mais contemplativa sobre o papel do enfermeiro na sessão de hemodiálise permitindo ao mesmo, conhecer e identificar as complicações que dificultam o processo de tratamento na hemodiálise.

Percebeu-se por meio do papel do enfermeiro e de sua atuação, que o nível de conhecimento adquirido pelos pacientes através das informações práticas fornecidas pelos enfermeiros se complementam promovendo meios da aplicabilidade na atuação do enfermeiro e do paciente, daí a necessidade e a importância de que seja feita a orientação e educação para que de fato o paciente amplie seus conhecimentos no tratamento a seu próprio benefício.

Constatou-se que o atendimento dado pelo enfermeiro ao paciente em tratamento possui um caráter motivador e importante para o sucesso do tratamento. Espera obter desse atendimento os subsídios necessários para a sua melhoria e bem-estar.

Os resultados desta pesquisa revelaram que os pacientes de fato precisam do acompanhamento do enfermeiro, necessitam da importância do papel desse profissional para melhor lhes auxiliar em suas dificuldades que na maioria das vezes estão relacionadas ao fato de não conseguirem relacionar as 
complicações ocorridas na sessão ao tratamento. $\mathrm{O}$ enfermeiro exerce grande importância no diagnóstico das complicações do paciente de hemodiálise.

Diante de tudo que foi exposto neste trabalho, demonstra-se a necessidade de realização de novos estudos em busca de compreender as variáveis que surgiram durante a sua realização, contribuindo assim para o enriquecimento dos materiais disponíveis para estudo, e que terá como resultado final uma assistência de enfermagem técnica, de qualidade e segura para o paciente durante a sessão de hemodiálise.

Este estudo possibilitou identificar a importância do enfermeiro no tratamento hemodialítico, tanto nas ações diretamente com as intercorrências como na relação enfermeiro-paciente, onde as orientações facilitam a adaptação deste ao novo hábito de vida, através do diálogo e da atenção que lhe são dados.

Percebe-se que há uma carência de trabalhos escritos por profissionais da enfermagem/enfermeiro, o que pode estar relacionado ao pouco número de pesquisas realizadas pela enfermagem nesta área.

Sugere-se que mais trabalhos sejam pesquisados e realizados com essa temática, pois é importante desenvolver ações que de fato contemplem o paciente e amplie o trabalho do papel do enfermeiro na sessão de hemodiálise.

\section{REFERÊNCIAS}

BARBOSA, G.S e VALADARES, G.C. Hemodiálise: estilo de vida e a adaptação do paciente. Acta paul. enferm., 2009, vol.22, no.spe1, p.524-527. ISSN 0103-2100

BARROS, E.; MANFRO, R. C.; THOMÉ, F. S. ,... [etel]. Nefrologia: rotinas, diagnóstico e tratamento. $2^{\mathrm{a}}$ ed. Porto Alegre: Artes Médicas, 1999.

CALIXTO RC, LORENÇON M, CORREAA MSMF, CRUZ AP, MARTINS LC, BARRETTI P, et al. Intercorrências Dialíticas em Hemodiálise. J Bras Nefro 2003.

CARVALHO, M.E. Publicação do Núcleo Avançado de Nefrologia e Diálise do Hospital Sírio-Libanês Julho/Agosto/Setembro - $20094^{\text {a }}$ edição.

CESARINO C. B. CASAGRANDE L. D. R. Paciente com insuficiência renal crônica em tratamento hemodialítico: atividade educativa do enfermeiro. Rev. Latino-Am. Enfermagem, 1998

CUPARRI, L. Guia de nutrição: nutrição clínica no adulto. Barueri, SP: Manoel, 2002.

DALGIRDAS J.T. Manual de diálise. 3a . Ed. Rio de Janeiro (RJ): Medsi; 2003

LIMA A. F. C, Gualda Dulce Maria Rosa. História oral devida:buscando o significado da hemodiálise para o paciente renal crônico. Rev.esc.enferm. USP . Set 35(3):235-241. 2001

MACHADO, LRC e CAR, MR. A dialética da vida cotidiana de doentes com insuficiência renal crônica: entre o inevitável e o casual. Rev. esc. enferm. USP, Set 2003, vol.37, no.3, p.27-35. ISSN 0080-6234 
MARTINS, C. Nutrição para pacientes em hemodiálise. 3. ed. UFPR, 1999.

MINAYO M. C. de S, org. Pesquisa Social: teoria, método e criatividade. Petrópolis: Vozes; 1994.

MINISTÉRIO DA SAÚDE (BR). Hemodiálise: Mais Dinheiro para Ampliar o Serviço. Brasília (DF); 2012. [acesso $2013 \quad$ Ago $\quad 23], \quad$ Disponível em:http://portalsaude.saude.gov.br/portalsaude/noticia/4458/162/recursos-para-hemodialise-aumentamem-r\$-1816-mi.html.

NASCIMENTO C. D, MARQUES I. R. Intervenções de enfermagem nas complicações mais frequentes durante a sessão de hemodiálise: revisão da literatura. Rev. bras. enfermagem. [periódico na Internet]. 2005 Dez [24];58(6):719-722. 2005

OLIVEIRA, S.M et al. Elaboração de um instrumento da assistência de enfermagem na unidade de hemodiálise. Acta paul. enferm., 2008, vol.21, no.spe, p.169-173. ISSN 0103-2100

PAOLUCCI, A. A. Et al. Nefrologia. Rio de Janeiro: Guanabara Koogan, 1977.

RIELLA, M. C. - Princípios de Nefrologia e Distúrbios Hidroeletrolíticos, 4 ed. Rio de Janeiro, Guanabara Koogan, 2003.

ROMÃO JUNIOR, J. E. Doença Renal Crônica: Definição, Epidemiologia e Classificação. JBN; 26 (3 -Supl 1):p1-3.USP, São Paulo 2004.

[1] Enfermeira graduada na cidade de Tucuruí-Pa. Concluinte do Curso de Especialização em Nefrologia da Faculdade Machado de Assis /FAMA-PA.

${ }^{[2]}$ Bióloga. Doutora em Ciências Biológicas - Área de Concentração Genética. Professora e Pesquisadora no CESUPA - Centro Universitário do Estado do Pará.

[3] Biomédica. Doutora em Doenças Tropicais. Docente e Pesquisadora da Universidade Federal do Amapá, AP. Pesquisador colaboradora do Núcleo de Medicina Tropical da UFPA (NMT-UFPA).

${ }^{[4]}$ Doutora em Psicanálise Clínica, Pesquisadora pelo Centro de Pesquisa e Estudos Avançados.

${ }^{[5]}$ Biólogo. Doutor em Teoria e Pesquisa do Comportamento. Docente e Pesquisador do Instituto Federal do Amapá - IFAP.

${ }^{[6]}$ Biólogo. Doutor em Medicina/Doenças Tropicais. Docente e Pesquisador na Universidade Federal do Pará - UFPA. Pesquisador no Laboratório de Toxicologia Humana e Ambiental e no Laboratório de Estresse Oxidativo do Núcleo de Medicina Tropical da UFPA (NMT-UFPA).

\section{PUBLIQUE SEU ARTIGO CIENTÍFICO EM:}

https://www.nucleodoconhecimento.com.br/enviar-artigo-cientifico-para-submissao 